\title{
SERVIÇO DE REFEIÇÕES ESCOLARES DA AUTARQUIA DE GONDOMAR: ANÁLISE DAS ATIVIDADES DE VERIFICAÇÃO
}

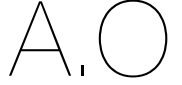

ARTIGO ORIGINAL

1 Faculdade de Ciências da Nutrição e Alimentação da Universidade do Porto, Rua do Campo Alegre,

n. ${ }^{\circ} 823$,

4150-180 Porto,

Portugal

2 Faculdade de Medicina da Universidade do Porto,

Alameda Prof. Hernâni

Monteiro

4200 - 319 Porto, Portugal

${ }^{3}$ Faculdade de Psicologia e de Ciências da Educação da Universidade do Porto, Rua Alfredo Allen,

4200-135 Porto, Portugal

4 CINTESIS

Rua Dr. Plácido da Costa,

4200-450 Porto, Portugal

*Endereço para correspondência:

Beatriz Teixeira

Faculdade de Ciências da

Nutrição e Alimentação d

Universidade do Porto,

Rua do Campo Alegre, n. 823

4150-180 Porto, Portuga

Histórico do artigo:

Recebido a 17 de julho de 2020 Aceite a 4 de setembro de 2020

\author{
SCHOOL MEALS SERVICE OF THE MUNICIPALITY OF \\ GONDOMAR: VERIFICATION ACTIVITIES ANALYSIS
}

Catarina Moreira'; Beatriz Teixeira ${ }^{1-3^{*}}$; Maria Cristina Teixeira Santos ${ }^{1,4}$

\section{RESUMO}

INTRODUÇÃo: Em Portugal a oferta das refeições escolares nas Escolas do $10^{\circ}$ Ciclo de Ensino Básico e Jardins de Infância é da responsabilidade das autarquias, tendo a maioria dos municípios do Norte de Portugal o serviço de oferta de refeições adjudicado. A segurança, qualidade e a quantidade dos alimentos produzidos/fornecidos/ingeridos nas escolas têm impacto na saúde das crianças, justificando atividades de verificação regulares.

OBJETIVOS: Análise das atividades de verificação do serviço de refeições escolares nas Escolas Básicas de $1 .^{\circ}$ Ciclo e Jardins de Infância da rede pública do Município de Gondomar.

METODOLOGIA: Foi desenvolvido um estudo observacional descritivo e retrospetivo, realizado entre setembro de 2016 e junho de 2018, relativo a 46 dos 84 estabelecimentos de ensino escolares da responsabilidade do município. Como instrumentos de trabalho, criaram-se duas bases de dados, uma para registo, categorização e análise das reclamações do serviço do fornecimento de almoços e lanches escolares. A outra base teve como finalidade o tratamento e análise dos registos dos relatórios da lista de verificação interna, que avalia condições de higiossanidade, técnicofuncionais e o cumprimento das cláusulas técnicas do caderno de encargos.

RESULTADOS: Constatou-se que não teve registos de atividades de verificação em todas as escolas. Verificou-se que os instrumentos de trabalho utilizados e criados abrangem a totalidade dos itens das cláusulas técnicas dos cadernos de encargos, possibilitando ainda a sua melhoria. A qualidade dos alimentos servidos obteve o maior número de reclamações ( $n=130$ ) e a "Zona de preparação e confeção" foi o domínio que apresentou um maior número de não conformidades (n=133).

CONCLUSÕES: A padronização dos procedimentos de monotorização e intervenção na avaliação do serviço de oferta de refeições e lanches da autarquia através da utilização de ferramentas de trabalho normalizadas é essencial para a melhoria da qualidade de serviço.

\section{PALAVRAS-CHAVE}

Caderno de encargos, Lista de verificação, Município, Reclamação

\section{ABSTRACT}

INTRODUCTION: In Portugal, the responsibility of school meals in Primary School and Kindergartens was transferred to the autarchies, with the majority of the municipalities in the North of Portugal having the meal offer service awarded. The safety, quality and quantity of food produced/supplied/ingested in schools have an impact on the health of children, justifying regular verification activities. OBJECTIVES: Analyze the verification activities of the school meal service in Primary Schools and Kindergartens within the public network of the Gondomar Municipality.

METHODOLOGY: A descriptive and retrospective observational study was carried out between September 2016 and June 2018 in 46 of 84 schools under the responsibility of the Municipality. As working tools, two databases were created, one for recording, categorizing and analyzing the complaints of the service that supplies schools' meals and snacks. And another database for processing and analyzing the internal checklist reports, which evaluates hygienic, technical and functional conditions and also the compliance with the technical clauses in the specifications.

RESULTS: It was found out that there were no records of verification activities in all schools. Besides, the working tools used and created cover the entirety of the technical clauses in the specifications, making possible their improvement. The quality of the food served received the largest number of complaints $(n=130)$ and the "Preparation and confectionery zone" was the one with the highest number of non-conformities ( $n=133$ ).

CONCLUSIONS: The standardization of procedures for monitoring and intervention the evaluation of the meal supply service and the rules of the municipality through the use of standardized work tools is essential for improving the quality of the service.

KEYWORDS

Specifications, Check List, Municipality, Complaint 


\section{INTRODUÇÃO}

O refeitório escolar tem uma importância fulcral no quotidiano dos alunos no que diz respeito à promoção de estilos de vida saudáveis $(1,2)$. A segurança, qualidade e quantidade de alimentos ingeridos em meio escolar têm um impacto elevado na saúde infantil (3), o que reforça a necessidade de uma constante educação alimentar e vigilância sanitária da oferta alimentar nas escolas (3-5).

Em Portugal, a responsabilidade das refeições escolares nas Escolas do $1 .^{\circ}$ Ciclo de Ensino Básico (EB1) e Jardins de Infância (JI) é das autarquias. (6). É, pois, sua competência assegurar o fornecimento $e$ a gestão dos refeitórios destes estabelecimentos $(7,8)$. Atualmente, grande parte dos municípios, tem o serviço de refeições escolares adjudicado a empresas de restauração coletiva (9). Esta adjudicação é, em geral, sustentada por um procedimento público em que os documentos mais relevantes são o programa do concurso e o caderno de encargos (CE) (6, 9). O Município de Gondomar (MG) em análise, apresenta, à data do estudo, 11 agrupamentos de escola (AE) e 84 estabelecimentos de ensino (23 EB1, 40 Jl e 21 EB1/JI). Deste universo de estabelecimentos, 17 escolas têm unidades de confeção (UC) e as restantes 67 unidades de distribuição (UD), sendo o serviço de oferta de refeições adjudicado a uma empresa de restauração coletiva. O MG possui 2 cadernos de encargos, um relativo ao fornecimento dos almoços e outro para os lanches $(10,11)$.

A análise de atividades de verificação quanto ao serviço de fornecimento de refeições escolares deve ser realizada de forma a: avaliar o desempenho geral dos refeitórios escolares; identificar as necessidades a melhorar/modificar e as tendências que indiquem uma maior incidência de produtos potencialmente não conformes e/ ou inseguros; estabelecer planos de ação, no âmbito da realização de auditorias internas, e identificar prioridades de atuação/intervenção (12). Salienta-se assim a importância do uso de atividades de verificação, para averiguar o desempenho/eficiência do serviço de oferta alimentar, através da recolha do máximo de informação possível e naturalmente articulada com o CE (9). Assim, a verificação que se entende como a confirmação, através da evidência objetiva, de que os itens especificados foram satisfeitos, é crucial nesta realidade (12). O MG tem à sua disposição dois tipos distintos de atividades de verificação no que diz respeito ao serviço de refeições escolares da sua responsabilidade: a receção e a análise de reclamações e as avaliações higiossanitárias que tem por base uma Lista de Verificação Interna (LVI) cuja análise é vertida em relatórios. No que diz respeito às reclamações, estas são rececionadas por correio eletrónico e os relatórios das LVI são realizados após as auditorias internas às cantinas escolares.

\section{OBJETIVOS}

Análise das atividades de verificação do serviço de refeições escolares em EB1 e Jl da rede pública do Município de Gondomar.

\section{METODOLOGIA}

\section{Tipo de Estudo e Espaço Temporal}

Estudo observacional, descritivo e retrospetivo, realizado entre setembro de 2016 e junho de 2018.

\section{Recolha de Informação e Metodologia \\ Seleção da amostra:}

$\mathrm{O} M \mathrm{MG}$ tem à sua responsabilidade 84 escolas (num total de $11 \mathrm{AE}$ ). A amostra abrange os registos de 46 escolas (de $10 \mathrm{AE}$ ), uma vez que são as que apresentam registos de dados de ocorrência e/ou relatórios da LVI.

Efetuou-se o levantamento de número de reclamações relativas à oferta alimentar, perfazendo um total de 55 ocorrências/reclamações, bem como de 51 relatórios da aplicação da LVI relativo às condições sanitárias e técnico-funcionais, ambos relativos aos períodos letivos de 2016/2017 e 2017/2018.

Criou-se e organizaram-se duas bases de dados em função para cada uma das atividades de verificação, para posterior análise.

- Base de Dados de Reclamações - Instrumento, em que foram tipificados 183 registos de reclamações recolhidos para caracterizar as 55 ocorrências, que resultou na criação de 5 domínios: "Não cumprimento de ementa" (NCE) com 2 tipificações "hortícola" e "sobremesa", "Qualidade/características organoléticas dos alimentos servidos" (QUAL) com 4 tipificações "pão ao lanche", "iogurte sólido", "queijo" e "manteiga", "Quantidade dos alimentos servidos" (QUAN) com 2 tipificações "hortícola" e "Fonte proteica", "Variedade dos alimentos servidos" (V) com 1 tipificação "sobremesa" e "Segurança Alimentar" (SA) com 2 tipificações "perigo biológico" e "perigo físico". - Base de Dados dos Relatórios da LVI da Higiossanidade - Relativa às condições higiossanitárias e técnicofuncionais das UC e UD organizada em função da LVI com 11 domínios, num total de 144 itens alvo de avaliação. Dez dos domínios são relativos às condições sanitárias: "Prérequisitos gerais do estabelecimento" (19 itens), "Zona de Receção e Armazenagem" (22 itens), "Equipamento de refrigeração e de conservação de congelados" (9 itens), "Zona de preparação e confeção" (37 itens), "Distribuição e Empratamento" (14 itens), "Equipamento de manutenção a quente" (3 itens), "Lavagem de material" (4 itens), "Controlo de Resíduos" (11 itens), "Instalações sanitárias e vestiários" (4 itens) e "Pessoal" (7 itens). Um dominio é relativo ao cumprimento das cláusulas técnicas do CE: "Serviço" (14 itens) (13).

\section{Tratamento e Análise de Dados}

Reclamações: Analisaram-se as variáveis: agrupamento de escola, escola, anos letivos, data de receção da reclamação, tipo de unidade, categoria e tipificação. Relatórios de avaliação da Higiossanidade relativos à LVI: Avaliaram-se os parâmetros: agrupamentos de escola, escola, anos letivos, tipo de unidade, domínios e itens alvo de avaliação. Procedeu-se à análise descritiva das variáveis dos diferentes domínios da LVI e da tipificação das reclamações, através da frequência das observações estatísticas e medida de tendência central (moda). Esta análise foi feita com recurso ao Software Microsoft Exce ${ }^{\circledR} 2016$.

\section{RESULTADOS}

\section{Caracterização da Amostra}

A amostra corresponde a 46 (55\%) do total das escolas do município e é constituída por registos de 18 (39\%) EB1, 13 (28\%) Jl e 15 (33\%) EB1/JI. Além disso, 11 (24\%) escolas apresentam registos da LVI, 9 (20\%) registos de ocorrências e 26 (56\%) apresentam ambos.

\section{Avaliação das Reclamações}

Os domínios QUAL, QUANT e NCE apresentaram maiores números de ocorrências (tipificações de reclamações): 130 (71\%), 32 (17\%) e 17 (9\%), respetivamente (Gráfico 1). Constata-se que as UD apresentam um maior número de tipificações de reclamações que as UC, 134 versus (vs.) 49, tendo-se destacado os domínios: QUAL (96 UD vs. 34 UC) e QUANT (23 UD vs. 9 UC). Da análise da moda dos itens alvo de avaliação por domínio, destaca-se, dentro do domínio QUAL o pão servido ao lanche ( $n=63)$, o iogurte sólido $(n=30)$ o queijo $(n=19)$ e a manteiga $(n=18)$. Relativamente à QUANT evidencia-se a baixa quantidade de hortícolas $(n=19)$ e de fonte proteica $(n=13)$ servidos ao almoço e, por fim, relativamente à categoria NCE é de salientar um maior incumprimento/inexistência de hortícolas ( $\mathrm{n=15}$ ) (Tabela 1). 
Tabela 1

Caracterização da tipificação das reclamações por dominio e das condições higiossanitárias por domínios da LVI, apresentando nomeadamente os 3 itens de cada domínio com maior número de não conformidades, verificadas no período entre setembro de 2016 e julho de 2018

\begin{tabular}{|c|c|c|c|}
\hline S RECLAMAÇÕES & N1 & $\%$ D1 & $\% \mathrm{~T} 1$ \\
\hline \multicolumn{4}{|c|}{ Não cumprimento da ementa (NCE) } \\
\hline Hortícola & 15 & $88 \%$ & $8 \%$ \\
\hline Sobremesa & 2 & $12 \%$ & $1 \%$ \\
\hline Total & 17 & $100 \%$ & $9 \%$ \\
\hline \multicolumn{4}{|c|}{ Qualidade/ Características organoléticas (QUAL) } \\
\hline Pão ao lanche & 63 & $48 \%$ & $34 \%$ \\
\hline logurte sólido & 30 & $23 \%$ & $16 \%$ \\
\hline Queijo & 19 & $15 \%$ & $11 \%$ \\
\hline Manteiga & 18 & $14 \%$ & $10 \%$ \\
\hline Total & 130 & $100 \%$ & $71 \%$ \\
\hline \multicolumn{4}{|c|}{ Quantidade (QUANT) } \\
\hline Hortícola & 19 & $59 \%$ & $11 \%$ \\
\hline $\begin{array}{l}\text { Fonte proteica (carne, pescado, ovos, } \\
\text { leguminosas) }\end{array}$ & 13 & $41 \%$ & $7 \%$ \\
\hline Total & 32 & $100 \%$ & $18 \%$ \\
\hline \multicolumn{4}{|c|}{ Variedade (V) } \\
\hline Sobremesa & 1 & $100 \%$ & $0,5 \%$ \\
\hline \multicolumn{4}{|c|}{ Segurança Alimentar (SA) } \\
\hline Perigo biológico & 2 & $67 \%$ & $1 \%$ \\
\hline Perigo físico & 1 & $33 \%$ & $0,5 \%$ \\
\hline Total & 3 & $100 \%$ & $1,5 \%$ \\
\hline Total de reclamações & 183 & $100 \%$ & $100 \%$ \\
\hline
\end{tabular}

\begin{tabular}{|c|c|c|c|}
\hline DoMíNIOS & N2 & $\% \mathrm{D} 2$ & $\% \mathrm{~T} 2$ \\
\hline \multicolumn{4}{|c|}{ Domínio 1: Pré-requisitos gerais do estabelecimento } \\
\hline Análise microbiológica às refeições, pessoal e superfícies & 26 & 33,3 & 6,5 \\
\hline Análise ao teor de proteínas e açúcares nas bancadas & 26 & 33,3 & 6,5 \\
\hline Análise aos compostos polares nos óleos de frituras & 26 & 33,3 & 6,5 \\
\hline \multicolumn{4}{|l|}{ Domínio 2: Zona de receção e armazenagem } \\
\hline $\begin{array}{l}\text { Dispositivos para desperdícios com tampa, acionamento não manual } \\
\text { e saco de plástico no interior }\end{array}$ & 40 & 47,1 & 10,0 \\
\hline Presença de insetocutor funcional & 31 & 36,5 & 7,8 \\
\hline Receção de produtos alimentares independente dos não alimentares & 14 & 16,5 & 3,5 \\
\hline \multicolumn{4}{|c|}{ Domínio 3: Equipamentos de refrigeração e de conservação de congelados } \\
\hline Existência de registos da temperatura dos equipamentos & 6 & 54,5 & 1,5 \\
\hline Presença de indicadores de temperatura & 3 & 27,3 & 0,8 \\
\hline $\begin{array}{l}\text { Equipamentos de conservação de congelados não é usado para a } \\
\text { congelação de produtos }\end{array}$ & 2 & 18,2 & 0,5 \\
\hline
\end{tabular}

Domínio 4: Zona de preparação e confeção

\begin{tabular}{|c|c|c|c|}
\hline $\begin{array}{l}\text { Dispositivos para lavagem das mãos, com água quente e fria, de } \\
\text { acionamento não manual, provido de sabonete líquido e meio de } \\
\text { secagem higiénica das mãos }\end{array}$ & 24 & 40,7 & 6,0 \\
\hline Presença de insetocutor funcional & 18 & 30,5 & 4,5 \\
\hline Existência de registos de descongelação & 17 & 28,8 & 4,3 \\
\hline \multicolumn{4}{|l|}{ Domínio 5: Distribuição e empratamento } \\
\hline Lavatórios não manuais e em $\mathrm{n} .^{\circ}$ suficiente & 11 & 55,0 & 2,8 \\
\hline Circuitos corretos- Marcha sempre em frente & 6 & 30,0 & 1,5 \\
\hline $\begin{array}{l}\text { Dispositivos de sabão (líquido) e sistema de secagem de mãos } \\
\text { higiénico }\end{array}$ & 3 & 15,0 & 0,8 \\
\hline \multicolumn{4}{|c|}{ Domínio 6: Equipamento de manutenção a quente e a frio } \\
\hline Equipamento em bom estado de higiene de salubridade & 3 & 33,3 & 0,8 \\
\hline $\begin{array}{l}\text { Géneros alimentícios protegidos de raios solares, poeiras e } \\
\text { conspurcações }\end{array}$ & 3 & 33,3 & 0,8 \\
\hline $\begin{array}{l}\text { Géneros alimentícios acondicionados a temperatura adequada/ } \\
\text { consignada }\end{array}$ & 3 & 33,3 & 0,8 \\
\hline \multicolumn{4}{|l|}{ Domínio 7: Lavagem de material } \\
\hline Separação entre copa suja e copa limpa & 3 & 42,9 & 0,8 \\
\hline Cubas adequadas com água quente e fria & 2 & 28,6 & 0,5 \\
\hline Máquina de lavar louça em bom estado de conservação e higiene & 2 & 28,6 & 0,5 \\
\hline \multicolumn{4}{|l|}{ Domínio 8: Controlo de resíduos } \\
\hline$N^{\circ}$ adequado de baldes do lixo & 3 & 50,0 & 0,8 \\
\hline Separação de resíduos para a reciclagem & 2 & 33,3 & 0,5 \\
\hline Localização adequada de baldes do lixo & 1 & 16,7 & 0,3 \\
\hline \multicolumn{4}{|c|}{ Domínio 9: Instalações sanitárias e vestiários } \\
\hline $\begin{array}{l}\text { Lavatórios com torneiras de acionamento não manual, com água } \\
\text { quente e fria, provido de sabonete líquido e meio de secagem } \\
\text { higiénica das mãos }\end{array}$ & 35 & 58,3 & 8,8 \\
\hline $\begin{array}{l}\text { Cacifos em número suficiente e em bom estado de conservação e } \\
\text { higiene }\end{array}$ & 17 & 28,3 & 4,3 \\
\hline $\begin{array}{l}\text { Instalações sanitárias separadas da zona de manipulação, em } \\
\text { número adequado e separados por sexo }\end{array}$ & 8 & 13,3 & 2,0 \\
\hline \multicolumn{4}{|l|}{ Domínio 10: Pessoal } \\
\hline Número de funcionários de acordo com as refeições confecionadas; & 9 & 42,9 & 2,3 \\
\hline Presença de declarações de aptidão médica dos funcionários & 7 & 33,3 & 1,8 \\
\hline Cumprimento das categorias e horário de trabalho & 5 & 23,8 & 1,3 \\
\hline \multicolumn{4}{|l|}{ Domínio 11: Serviço } \\
\hline $\begin{array}{l}\text { Ementa executada nas porções corretas- correto fornecimento de } \\
\text { capitações }\end{array}$ & 15 & 36,6 & 3,8 \\
\hline Verificação do acompanhamento de produtos hortícolas no prato & 14 & 34,1 & 3,5 \\
\hline Empacotamento dos talheres & 12 & 29,3 & 3,0 \\
\hline
\end{tabular}

N1: Número total de tipificações do universo total das 183 tipificações de reclamações

\%D1: Percentagem que a categorização apresenta dentro do seu domínio

\%T1: Percentagem que a categorização apresenta no total de tipificações de reclamações

N2: Número total de não conformidades de cada item

\%D2: Percentagem que a categorização apresenta dentro do seu domínio

\%T2: Percentagem que a categorização apresenta no total de itens da Lista de Verificação Interna 


\section{Gráfico 1}

Total de Reclamações (n) por Domínios entre setembro de 2016 e julho de 2018

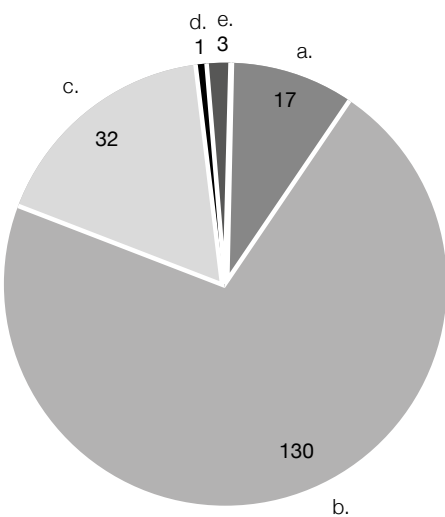

a. Não cumprimento das ementas

b. Qualidade/Características organoléticas dos alimentos servidos

c. Quantidade dos alimentos servidos

d. Variedade dos alimentos servidos

e. Segurança alimentar

\section{Gráfico 2}

Total de Não Conformidades (n) por Domínios de Lista de Verificação Interna entre setembro de 2016 e julho de 2018

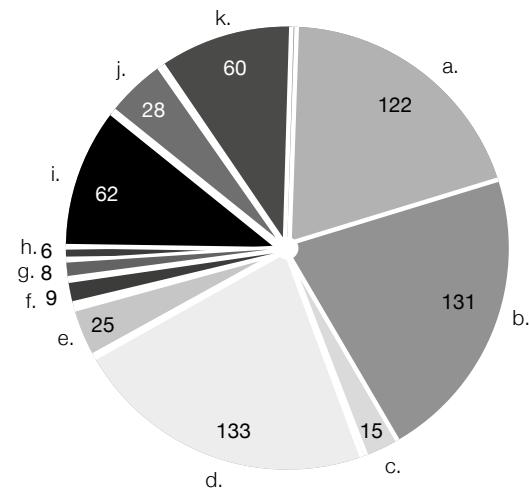

a. Pré-requisitos gerais do estabelecimento

b. Zona de receção e armazenagem

c. Equipamentos de refrigeração e de conservação de congelados

d. Zona de preparação e confeção

e. Distribuição e empratamento

f. Equipamento de manutenção a quente e a frio

g. Lavagem de material

h. Controlo de resíduos

i. Instalações sanitárias e vestiários

j. Pessoal

k. Serviço

\section{Avaliação da Higiossanidade}

Todos os requisitos do CE em matéria de higiossanidade estão representados na LVI. Os domínios da LVI com maior número de NC foram, por ordem decrescente: "Zona de preparação e confeção", "Zona de receção e armazenagem", "Pré-requisitos gerais do estabelecimento", "Instalações sanitárias e vestiários" e "Serviço", com um valor de NC de, respetivamente, 133,131,122,62 e 60 (Gráfico 2). Relativamente às NC por domínio, destacam-se, no $1 .^{\circ}$ domínio referido, NC relativas às análises periódicas, nos itens: "Análise Microbiológica às refeições, pessoal e superfícies"; "Análise ao teor de proteínas e açucares nas bancadas" e "Análise aos compostos polares nos óleos de fritura" ( $n=26$ para os 3 itens); no domínio "Zona de receção e armazenagem", o item "Dispositivos para desperdícios com tampa, acionamento não manual e saco de plástico no interior" ( $n=40)$; no domínio "Pré-requisitos gerais do estabelecimento", o item "Dispositivos para lavagem de mãos, com água quente e fria, de acionamento não manual, provido de sabonete líquido e meio de secagem higiénica das mãos" ( $n=24)$; no domínio "Instalações sanitárias e vestiários", o item "Lavatórios com torneiras de acionamento não manual, com água quente e fria, provido de sabonete líquido e meio de secagem higiénica das mãos" ( $n=35)$ e, no domínio "Serviço", os itens "Ementa executada nas porções corretas - correto fornecimento de capitações" e "Verificação do acompanhamento de produtos hortícolas no prato" ( $n=15$ e $n=14$, respetivamente). Estes dados encontram-se presentes na Tabela 1, que apresenta os três itens com maior número de NC existentes em cada domínio.

\section{DISCUSSÃO DOS RESULTADOS}

Relativamente à caracterização da amostra salienta-se que, apesar da amostra ter uma representatividade de $55 \%$ em relação ao número total de escolas da autarquia, o número de registos de atividades de verificação presente é escasso, tendo em conta que nem todas as escolas são avaliadas pelo menos uma vez, o que pode ser explicado pela falta de recursos humanos e especializados para o exercício desta atividade.

\section{Avaliação das Reclamações}

Os domínios com mais reclamações (QUAL, QUANT e NCE) vão de encontro ao descrito no "Relatório do Plano Integrado de Controlo da Qualidade e Quantidade das Refeições Escolares", mais especificamente, no que concerne à Direção dos Serviços da Região Norte (14).

Relativamente à evidência das UD apresentarem um maior número de reclamações que as UC, esta pode ser explicada pelo facto das refeições transportadas obrigarem a uma logística de processos/ procedimentos, que contemplam equipamento específico, designadamente veículos e material de acondicionamento. O maior número de reclamações no domínio QUANT nas UD, pode justificar-se pelo incumprimento do $\mathrm{CE}$, no capítulo II, cláusula n. ${ }^{\circ} 21$, ponto 2 "Para as escolas sem cozinha, as refeições deverão ser levantadas na cozinha polo, a partir das 11:00h e transportadas, pelo adjudicatário, até as salas de refeições, para que o horário das refeições mencionado no n. ${ }^{\circ} 3$ da cláusula $1 .^{a}$ desta peça de procedimento, seja respeitado. Deverá existir um acréscimo de fornecimento de cerca de 10\% da quantidade, inclusive na sobremesa, relativamente às quantidades" (10). É consensual que as variáveis temperatura e tempo são cruciais à condição de manipulação a ter em conta numa oferta alimentar desta natureza (15-17), o que dada a realidade do incumprimento pode justificar as alterações organoléticas alvo de reclamação. As refeições das UD encontram-se mais suscetíveis à contaminação por 
microrganismos e à sua posterior proliferação, se as boas práticas de higiene e fabrico não forem rigorosas, bem como, à perda de propriedades sensoriais e nutricionais durante o transporte $(18,19)$. De um modo geral, o número de reclamações no domínio QUANT, pode ser explicado pelo incumprimento da correta capitação prevista no $\mathrm{CE}$ uma vez que as reclamações se referiam à pouca quantidade de fonte proteína fornecida. Outra justificação poderá ser a eventual baixa literacia alimentar/nutricional quanto às corretas porções a serem servidas na refeição por parte da comunidade escolar nomeadamente encarregados de educação e pessoal técnico. Como tal, seria interessante a realização de formação in loco às cozinheiras, de forma a minimizar os erros sobre as capitações a fornecer no empratamento e não menos importante a toda a comunidade escolar.

Ademais, em função do elevado número elevado de reclamações nas UD em relação às UC, sugere-se averiguar as condições de transporte (higiene, manipulação, acondicionamento e percurso) e controlar as horas a que a refeição sai da UC e chega às respetivas UD.

A informação na literatura relativa à caracterização do serviço de fornecimento de lanches pelas autarquias é escassa, não existindo, até ao momento, dados relativos às reclamações desta refeição. Neste trabalho, sendo a maioria das reclamações relativa aos lanches e às suas características qualitativas, nomeadamente a vertente organolética, seria interessante averiguá-las, bem como as condições de transporte no sentido de saber se estas foram/serão as responsáveis por estas ocorrências $(17,20,21)$.

\section{Avaliação da Higiossanidade}

O conhecimento das condições sanitárias fornece informações quanto às boas práticas, higiene, segurança e manutenção da qualidade do alimento ou dos instrumentos que contactam com os alimentos e o pessoal afeto à manipulação. Assim, e devido ao elevado número de NC relativas a estes parâmetros, particularmente, a ausência de análises microbiológicas periódicas, alerta-se para a importância da realização das mesmas, bem como para a necessidade de existência de um procedimento de verificação periódico baseado em análises microbiológicas adaptado à realidade, que permita monitorizar/ verificar as condições sanitárias das refeições e meio envolvente, designadamente nas unidades de confeção e distribuição e a qualidade do ar interior $(22,23)$.

Este trabalho alerta para a relevância de uma prática correta de manipulação dos desperdícios $(24,25)$, uma vez que se constatou que era o item do domínio "Zona de receção e armazenagem" com maior número de NC, reforçando-se a importância do uso correto dos dispositivos de lavagem de mãos. O incumprimento deste item favorece oportunidades de contaminações cruzadas e permanência de microrganismos nas mãos dos manipuladores, o que vai ao encontro da investigação de Santos et al (26). Na investigação de Pagotto et al (27), o défice de conhecimento relativo a boas práticas de higiene e fabrico, particularmente na manipulação, é responsável pela realização incorreta das práticas de manipulação.

Os itens em destaque do domínio "Serviço" permitem efetuar um paralelismo entre o domínio QUANT das reclamações nos itens "incumprimento da ementa" e "quantidade de hortícolas". Verificou-se um incumprimento de $17 \%$ relativo ao "incumprimento da ementa" e $10 \%$ de NC no item "Ementa executada nas porções corretas - correto fornecimento de capitações". Já na segunda associação, "quantidade de hortícolas" vs. "Verificação do acompanhamento de produtos hortícolas no prato" os dois apresentaram $8 \%$ de reclamações e NC. Apesar de não ser possível medir nem estabelecer a associação entre estas atividades de verificação, a coincidência é notória e esperada no incumprimento destes itens.

Como principais limitações deste estudo destacam-se a ausência de relatórios da LVI de todas as escolas; a inexistência de um procedimento padronizado de verificação relativamente à periodicidade de visitas às cantinas não permitindo obter informação relativa ao desempenho (número total de NC por domínio e item alvo de avaliação) de cada unidade, bem como à evolução do mesmo; e o modo menos bem organizado e gerido de como chegam as ocorrências ao núcleo da saúde em tempo útil. Evidencia-se de forma positiva a utilidade da criação de instrumentos de trabalho padronizados; monotorização/ verificação das atividades de verificação; a importância da utilidade futura para o trabalho do nutricionista na autarquia, através da criação de uma estrutura organizacional relativa à gestão da documentação que permita, em tempo real, ter informação factual que espelhe a realidade dos serviços de fornecimento de almoços e lanches escolares $(28,29)$.

Como considerações finais, apresentam-se algumas sugestões de melhoria. Assim, salienta-se a necessidade de reforçar a padronização dos procedimentos de monotorização/verificação e intervenção na avaliação do serviço de oferta alimentar da autarquia, que se traduzirá na melhoria da qualidade de serviço, visto que a normalização potencia o rigor e a diminuição de falhas quer na operacionalização quer na verificação, tendo em conta que os critérios subjacentes a utilizar serão os mesmos (30-33). Evidencia-se a necessidade da criação de um plano de atividades de verificação que defina a periocidade da sua execução. Como a autarquia dispõe de um nutricionista para, à data, monitorizar 84 escolas sugere-se uma periodicidade mínima de 6 em seis 6 meses a UD e de 3 em 3 meses a UC, de forma a controlar os parâmetros de segurança e qualidade alimentar.

Dado que a LVI não é nem valorada nem quantificada, não permite resultados quantitativos, o que seria uma mais valia para todo o diagnóstico e para a indicação da prioridade de intervenção $(33,34)$ preconiza-se a sua quantificação e valoração dos domínios em função do compromisso na segurança alimentar, bem como no cumprimento das cláusulas técnicas dos cadernos de encargos.

Quanto às reclamações, sugere-se a criação de uma linha direta de telefone/e-mail de forma a toda a comunidade escolar ser capaz de efetuar, se necessário, o registo de uma ocorrência e, com isto, reduzir o tempo de chegada das reclamações ao nutricionista, o tempo de resposta às mesmas e, sobretudo, a perda de informação. Propõe-se ainda a aplicação de um questionário de satisfação relativo à oferta alimentar dos almoços e lanches escolares para coordenadores de escola, a ser aplicado, no mínimo, uma vez por período e, aos encarregados de educação (via online), com o intuito de se obter informação adicional relativamente ao desempenho do serviço de refeições escolares.

\section{CONCLUSÕES}

Este estudo permitiu analisar as atividades de verificação reclamações e avaliações higiossanitárias - do serviço de refeições escolares em 46 (55\%) escolas do MG. Foi possível constatar que a categoria Qualidade, designadamente características organoléticas, foi a que obteve uma maior percentagem de reclamações (71\%) e o domínio "Zona de preparação e confeção" foi o que apresentou um maior número de NC relativamente às condições higiossanitárias. Concluiu-se que a padronização dos procedimentos de monotorização/ verificação e a intervenção na avaliação do serviço de oferta alimentar através do uso de ferramentas padronizadas é crucial para a melhoria da qualidade do serviço da oferta de refeições. 


\section{AGRADECIMENTOS}

A equipa de investigação agradece ao Exmo. Sr. Presidente da Câmara de Gondomar, Dr. Marco Martins, às Exmas. Sras. Vereadoras, Dra. Cláudia Vieira do Departamento de Coesão Social e Dra. Aurora Vieira do Departamento da Educação e Recursos Humanos, à Exma. Sra. Secretária de Apoio à Vereação, Dra. Inês Silva, à Dirigente Intermédia do Núcleo de Saúde, Dra. Antónia Ferreira bem como o contributo da Dra. Joana Barroso, nutricionista.

\section{REFERÊNCIAS BIBLIOGRÁFICAS}

1. Direção Geral da Educação. Orientações sobre ementas e refeitórios escolares 2013/2014. Direção Geral da Educação 2013.

2. Lima, R. Orientações sobre Ementas e Refeitórios Escolares Ministério da Educação Direção Geral da Saúde. 2018.

3. Baptista M, Lima R. Educação Alimentar em Meio Escolar. Referencial para uma oferta alimentar Saudável Direção Geral de Inovação e do Desenvolvimento Curricular Lisboa, 2006.

4. Direção Geral do Consumidor. Associação Portuguesa dos Nutricionistas. Guia para educadores - Alimentação em idade escolar. Direção Geral do Consumidor. Associação Portuguesa dos Nutricionistas. Disponível em https://wwwapnorgpt/documentos/ guias/GuiaAPN_AlimentacaoldadeEscolarpdf. 2013.

5. World Health Organization. Food and nutrition policy for schools- A tool for the development of school nutrition programmes in the European Region. 2006.

6. Ministério da Educação, DGEstE. Fornecimento de Refeições em Refeitórios Escolares - Caderno de Encargos. DGEstE/ASE/AQ15-RC/2014. 2014.

7. Assembleia da República. Lei n. 159/99. Diário da República n 215/1999, Série I-A de 1999-09-14; 6301 - 07. 1999

8. Camarinha B, Ribeiro F, Graça P. O papel das Autarquias no Combate à Obesidade Infantil. Acta Portuguesa de Nutrição. 2015, 1:6-9.

9. Rocha A, Ávila H, Marinho M. Avaliação dos Cadernos de Encargos dos Municípios Portuguese para o Fornecimento de Refeições Escolares. Revista Nutrícias. 2012;12-16. 10. Caderno de Encargos da Câmara Municipal de Gondomar. Concurso Público CP 03/17- Fornecimento de Refeições Escolares às Escolas do $1^{\circ}$ Ciclo do Ensino Básico e aos Jardins de Infância. 29 de março de 2017.

11. Caderno de Encargos da Câmara Municipal de Gondomar. Concurso Público CP 08/17- Aquisição de Serviços para o Fornecimento de Lanches Durante o Período de Alargamento de Horário dos Alunos dos Estabelecimentos de Educação PréEscolar. janeiro 2016.

12. NP EN ISO 19011:2019. Linhas de orientação para auditorias a sistemas de gestão. IPQ 2019

13. Câmara Municipal de Gondomar. Lista de Verificação Interna da CMG. 2017.

14. Ministério da Educação, DGEstE. Plano integrado de Controlo da Qualidade e Quantidade das Refeições Escolares - Relatório. Lisboa 2018.

15. Rocha A, Ávila, H, Barbosa M.Caracterização da Prestação do Serviço de Refeições Escolares pelos Municípios Portugueses. RevistaNutrícias.2012;13:3-8.

16. Associação Portuguesa de Hotelaria. Código de boas práticas de higiene e segurança alimentar. Aplicação dos princípios de HACCP a Hotelaria e Restauração. 2004.

17. WHO, FAO. Codex Alimentarius Comission. 21 ed Procedural manual Rome, 2013. 18. PARLAMENTO EUROPEU E O CONSELHO DA UNIÃO EUROPEIA. Anexo 2 do REGULAMENTO (CE) N. ${ }^{\circ}$ 852/2004 DO PARLAMENTO EUROPEU E DO CONSELHO de 29 de Abril de 2004 Jornal Oficial da União Europeia 2004.

19. Associação da Restauração e Similares de Portugal. Código de Boas Práticas para o Transporte de Alimentos. Associção da Restauração e Similares de Portugal. 2008. 20. WHO, FAO. Code of hygienic practice the transport of food in bulk and semipacked foof. CAC/RCP 47-2001. 2001.

21. WHO, FAO. Code of hygienic practice for milk and milk produts. CAC/RCP $57-$ 20042004.

22. WHO, FAO. Principles and guidelines for the conduct of microbiological risk management (MRM). CAC/GL 73-2007 2007.
23. Grupo de Trabalho Ocorrência Microbiológica na Cadeia Alimentar. Guia para o Estabelecimento de Critérios Microbiológicos em Géneros Alimentícios PortFIR. 2017. 24. Carvalho J, Roriz M, Liz M. Higiene e Segurança Alimentar em Serviços de Alimentação de Escolas Básicas de $1^{\circ}$ Ciclo. . Acta Portuguesa de Nutrição. 2015. 25. Correia J, Silva S, Santos C. Serviço de Refeições Escolares num Município: Avaliação da Higiossanidade e de Ementas em Unidades de Gestão Direta. . Aliment Hum 2014;2014; 20(2 e 3):47-59.

26. Santos M, Nogueira J, Mayan O. Condições higio-sanitárias das cantinas escolares do distrito de Vila Real. Revista Portuguesa de Saúde Pública. 2007;25(2).

27. Pagotto HZ, Espíndula LG, Vitória AG, Machado MCMM, São José JFB. Nível de conhecimento, atitudes e práticas dos manipuladores de alimentos em serviços de alimentação. Demetra: Alimentação, Nutrição \& Saúde. 2018;13(1); 293-305 28. Lobato L. Análise de risco e avaliação higio-sanitária de refeitórios escolares : Trabalho de Investigação : Risk analysis; Hygiene and Sanitary Conditions of School Canteens. [Tese de Licenciatura] Porto: Faculdade de Ciências da Nutrição e Alimentação da Universidade do Porto. Disponível https://hdlhandlenet/10216/54687. 2009.

29. Marinho AR. Fiscalização municipal e análise de risco : trabalho de investigação: Municipality Inspection and risk analysis. [Tese de Licenciatura] Porto: Faculdade de Ciências da Nutrição e Alimentação da Universidade do Porto. Disponível http:// hdlhandlenet/10216/54734. 2009.

30. NP EN ISO 9000: 2015. Sistemas de Gestão da Qualidade. Fundamentos e Vocabulário. IPQ 2015

31. ISO 22000: 2018 (E). ISO 2018. Sistemas de Gestão da Segurança Alimentar. Requisitos para qualquer organização que opere na cadeia alimentar. NP EN ISO 19011:2019.

32. Parlamento Europeu e Conselho da União Europeia. Regulamento (CE) n. ${ }^{8852 / 2004 . ~}$ Jornal Oficial das Comunidades Europeias L 139/55 (2004-04-29), relativo à higiene dos géneros alimentícios.

33. Afonso C, Santos MCT, Morais C, Franchini B, Chilro R, Rocha A. SISTEMA DE PLANEAMENTO E AVALIAÇÃO DE REFEIÇÕES ESCOLARES - SPARE. Alimentação Humana. 2011; Volume $17 \cdot N^{\circ} 1 / 2 / 3$

34. Lobato L, Santos C. GRELHAS DE AVALIAÇÃO HIGIO-SANITÁRIA DE REFEITÓRIOS ESCOLARES. Alimentação Humana. 2010 Volume $16 \cdot$ № 1. 